\title{
Santorini unrest 2011-2012: an immediate Bayesian belief network analysis of eruption scenario probabilities for urgent decision support under uncertainty
}

Willy P Aspinall ${ }^{1,2^{*}}$ and Gordon Woo ${ }^{3}$

\begin{abstract}
Unrest at the Greek volcanic island of Santorini in 2011-2012 was a cause for unease for some governments, concerned about risks to their nationals on this popular holiday island if an eruption took place. In support of urgent response planning undertaken by the UK government, we developed a rapid evaluation of different eruption scenario probabilities, using the Bayesian Belief Network (BBN) formulation for combining multiple strands of scientific and observational evidence. Here we present three alternative BBN models that were devised in early 2012 for assessing the situation: (1) a basic static net for evaluating probabilities at any one moment in time, utilising just four key unrest indicators; (2) a compound time-stepping net, extending the basic net to update probabilities through time as the indicators changed; and (3) a more comprehensive net, with multiple lines of other data and observations incorporated, reflecting diversity of modern multi-parameter monitoring techniques. A key conclusion is that, even with just three or four basic indicators, it is not feasible, or defensible, to attempt to judge mentally the implications of signs of unrest - a structured probabilistic procedure using Bayes' Rule is a rational approach for enumerating evidential strengths reliably. In the Santorini case, the unrest, and official anxiety, diminished quite quickly and our approach was not progressed to the point where detailed consideration was given to BBN parameters, analysis of data uncertainty or the elicitation of expert judgements for quantifying uncertainties to be used in the BBN. Had this been done, the resulting scenario probabilities could have been adopted to determine likelihoods of volcanic hazards and risks caused by possible eruptive activity, as identified in a concurrent assessment of the scale and intensities of potential volcanic impacts (Jenkins et. al., Assessment of ash and gas hazard for future eruptions at Santorini Volcano, Greece. forthcoming). Ideally, such hazard and risk assessments should be elaborated in detail and critiqued well before crisis-level unrest develops - not initiated and implemented within a few hours just when a situation looks ominous. In particular, careful analysis of all information is required to determine and represent parameter uncertainties comprehensively and dependably.
\end{abstract}

Keywords: Bayes' rule; Bayesian belief network; Decision support; Emergency preparedness; Probabilistic uncertainty; Volcanic hazard assessment

\footnotetext{
* Correspondence: willy.aspinall@bristol.ac.uk

${ }^{1}$ School of Earth Sciences and Cabot Institute, University of Bristol, Wills Memorial Building, Queen's Road, Bristol BS8 1RJ, UK

${ }^{2}$ Aspinall \& Associates, Cleveland House, High Street, Tisbury SP3 6HF, UK

Full list of author information is available at the end of the article
} 


\section{Background}

In January 2011, there was a sharp increase in seismic activity beneath the Kameni islands in the Santorini caldera (Thera), and surface deformation was detected that was interpreted as the inflation of a magmatic source (Newman et al. 2012; Papoutsis et al. 2013). While the most common presumption was that the unrest was due to magmatic intrusion at shallow depth, it is also plausible that it was a result of wider tectonic stresses, and not simply or necessarily solely volcanic in origin. If this possibility is ignored or discounted - something that can easily happen, say, with volcanologists in crisis mode focusing on their specialism - the corollary is that volcanic hazard levels might be over-stated. Moreover, assuming just the magmatic driver interpretation and ignoring tectonic seismic hazard levels could be even more dangerous: whereas volcanic activity would cause severe disruption on the island and could entail several casualties, a strong local earthquake might result in hundreds of deaths and casualties. Thus the 2011-2012 seismic unrest situation at Santorini was one where either one or both hazards could have developed (and may still do so).

At the time, the geophysical unrest at Santorini was a significant concern for some governments and the European Community. They were worried about risks to their nationals if a volcanic eruption took place, and needed to plan to respond to ensure safety. The principal challenge would be evacuating large numbers of people from a small island with limited scope for transportation and other logistic action, especially if the local airfield was affected by ash. It was in this context that volcanological advice was sought from a number of scientists as part of official UK government response planning activities ${ }^{\mathrm{a}}$. This report outlines the way in which the emerging evidence and data about the unrest, which were uncertain and time-varying, could be interrogated to provide provisional eruption probability estimates for decision support. Because it offers a rational evidence-based formalism, the Bayesian Belief Network (BBN) formulation was chosen as an appropriate conceptual tool for weighing the various different strands of evidence and their specific diagnostic powers as eruption precursors. Furthermore, the ways in which all related uncertainties are characterized, assessed and treated jointly - and how they change with time are, in effect, catalogued by the BBN; this record can be scrutinized post hoc to gain insights into the evolution of a natural hazard crisis and the cues that precursors provide. The formalism is illustrated here for enumerating probabilities of different volcanic hazard-initiating events at Santorini by encompassing the varied - and sometimes confounding - indications of unrest in the objective framework of a BBN.
Quantitative multi-risk analysis using current methodologies presents many challenges (e.g. Kappes et al. 2012; Marzocchi et al. 2012). For disaster officials, scenarios are often perceived just in descriptive terms, sometimes relate to one reference event type only (e.g. flood, earthquake, windstorm or eruption) and rarely consider the possibility of joint or cascaded hazard exposures and the associated uncertainties, physical, scientific and logistical. In the case of Santorini, the basis and provisional findings of a counterpart appraisal of short-term earthquake risk, undertaken for the UK government at the same time as the volcanic eruption assessment, will be presented elsewhere. Here we focus on the eruption assessment challenge.

\section{Methods - Bayesian belief networks}

Bayesian Belief Networks (also called Bayes nets or causal networks) are increasingly being used in natural hazards work as a method for reasoning about causal influences under conditions of observational uncertainty and for modelling uncertain domain states and conditions. BBNs were pioneered in medical decision support systems (Spiegelhalter et al. 1993) and are finding growing application for insurance and operational risks (e.g. Neil et al. 2005; Cowell et al. 2007), in environmental modelling (Aguilera et al. 2011), and in determining the value of scientific information for climate change assessment (Kousky and Cooke 2012). The principles of the BBN concept are not outlined here, but can be found in the literature (e.g. Darwiche 2009; Jensen et al. 2010; Fenton and Neil 2012) - the key appeal of a $\mathrm{BBN}$ is that it implements Bayes' Rule and executes all the necessary, and numerically non-trivial, calculations within an intuitive graphical construct.

BBN graphs are a direct visual representation of states of the world, not of reasoning processes in the sense of artificial intelligence; participating elements (processes, factors) are identified as nodes, joined where valid by directed arcs (arrows) denoting real causal connections. However, arc arrowheads on a BBN do not show the direction of flow of information during reasoning (as in neural networks or rule-based systems), because information can be propagated both forwards and backwards. In the present case, we design our BBN to reason in probability terms backwards from observations of unrest - that is, from information which we can acquire about effects to the fundamental cause, i.e. a volcano's eruptive state or condition, the controlling factor or property of interest which cannot be measured directly.

Another important attribute of the BBN for volcanic hazards assessment is the capability it offers to include expert judgements in the evidential mix, together with observational data, empirical relationships or model outcomes (e.g. Hincks, 2007; Hincks et al. 2014). Moreover, the $\mathrm{BBN}$ has the property that it can incorporate negative evidence (e.g. a cessation of gas flux), and can account for 
situations where information is only partially complete (e.g. when an instrumental data stream drops out).

The flexible structure and unique modelling techniques offered by a Bayesian network makes it possible to analyse hazards in full probabilistic terms, capturing interactions between geophysical variables and associated uncertainties. This is especially valuable where substantial elements of scientific judgement are involved, as, almost invariably, they are with natural hazards. In particular, the methodology is well suited for treating uncertainties associated with internal volcanic processes, not accessible for direct measurement from the Earth's surface. Inferences about internal system states and probabilities of consequent hazard events can be updated rationally, and proportionately, on the basis of new observations or new information.

In the present case, quantitative scenario modelling using a Bayesian network has several important features:

(1) It is probabilistic, rather than deterministic unavoidable uncertainties in the parameters and their inter-relationships can be represented by probability distributions.

(2) Physical models, statistical data and expert judgement all can be incorporated jointly with the Bayesian network.

(3) A large number of parameters and their inter-relationships can be considered in a systematic way with the network.

(4) The probabilities of one parameter can be updated via added information, while a change in one parameter will influence others in the network through the defined causal inter-relationships.

The principles behind Bayes' Rule - as an applicable logical precept for weighing evidence for hazard assessment under uncertainty and as the basis for BBN calculations were introduced into volcanology by Newhall and Hoblitt (2002), and further elaborated by Aspinall et al. (2003, 2006); a BBN framework has been used in a retrospective analysis of the 1976 Guadeloupe volcano crisis episode (Hincks et al. 2014). Complementary approaches for characterizing eruption scenario probabilities include logic or event trees (e.g. Newhall and Hoblitt 2002; Marzocchi et al. 2004, 2008; Sobradelo and Marti 2010) - these are generally designed to capture a sequence of events and observations rather than describe primary physical, petrological and geochemical states and make inferences about process interactions and conditions. However, the basic probability calculus is largely the same.

Inferring potential volcanic activity scenario probabilities from unrest observations: Santorini 2011-2012

We now illustrate some of the ways the BBN formulation can be used in situations of suspected volcanic unrest to evaluate multiple strands of observational evidence and data with the purpose of inferring relative probabilities for different potential eruption scenarios or, indeed, for an outcome of no eruption. We use the case of the 2011-2012 unrest at Santorini as a basis for demonstration with the Netica package (NorsysSoftware Corp. 2014); however, all values and probabilities reproduced in what follows were chosen as provisional indicative numbers - had the crisis escalated further these would have been subjected to detailed expert appraisal and modulation.

In brief, there was an increase in local seismicity within the Thera caldera in early 2011, accompanied by inflationary deformation centred in the caldera, with seismicity escalating and inflation increasing over subsequent months (e.g. Newman et al. 2012; Feuillet 2013; Papoutsis et al. 2013). Other narrative signs of unrest, such as unusual bubbling in the water and a temperature rise, were also reported. By the end of 2011 into early 2012, levels of activity were sufficiently strong to cause scientific and official concern about the possibility of a volcanic eruption ensuing in the near future.

Here we present three variants of our BBN model, configured for the Santorini situation: (1) a basic net for evaluating eruption probabilities at one moment in time, utilising four traditional key indicators for unrest due to volcanic activity; (2) the same basic net, extended to illustrate how eruption probabilities can be updated through time as these indicators change; and (3) a more complex single instant net, in which multiple lines of other data are added to reflect the diversity and differential evidential worth of modern monitoring techniques.

\section{Basic BBN for Santorini 2011-2012}

In the discussion that follows, illustrative parameters and values are used in the BBNs. These were chosen by one of us (WPA), in extreme haste over a few hours, for the purposes of providing indicative eruption probabilities in support of urgent advice required by the UK government. Whilst the parameters are, in volcanological terms, informed up to a point, they were nevertheless decided without the benefit of detailed factual investigation, data analysis or wider expert inputs, so the numerical aspects of our BBNs should be viewed in this light.

Figure 1 shows an elementary four observables BBN constructed for the Santorini crisis, compiled originally in January 2012 when concern about eruption potential was high. The top level target node Santorini_eruption_probs comprises four alternative possible 'class scenarios', each carrying very different implications for mitigating and responding to related hazards. The four classes are labelled: Non magmatic, Failed intrusion, Lava flow or dome 1st and Explosion 1st.

The latter two eruption types were chosen as separate reference classes, guided by the knowledge (e.g. Siebert et al. 2010) that Santorini volcano has, in the past, 


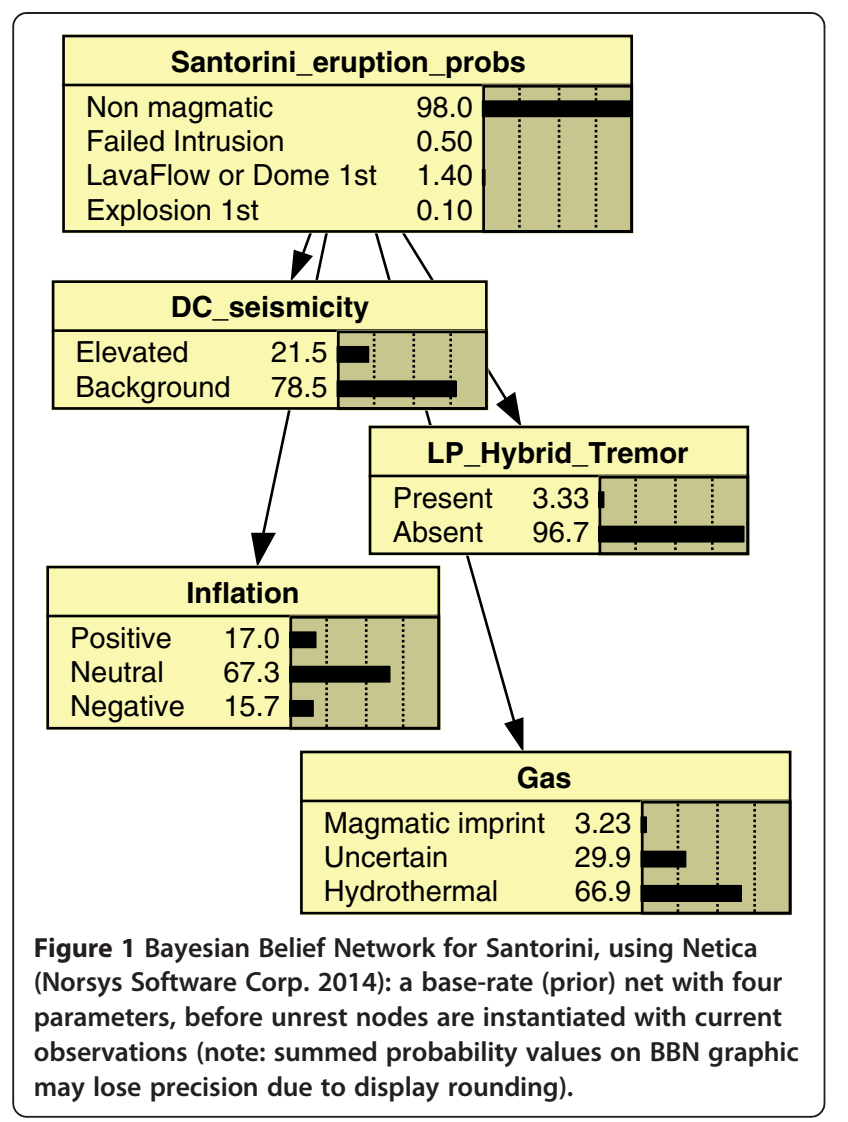

exhibited two distinct eruptive styles: small, effusive eruptions, which occur relatively frequently and build shields and domes of lava; and large explosive eruptions that occur rarely, at intervals of 10,000-30,000 years.

In order to parameterize the $\mathrm{BBN}$, our first task was to pull together available evidence to provide a basis for quantifying the long-term base rate of eruptions of Santorini. For the purposes of the BBN assessment, we defined an "imminent eruption" as meaning one that could occur during the (then) calendar year 2012 (our analysis being performed close to the start of that year). For data on recurrence intervals we turned to the work of Pyle and Elliott (2006) on the evolution of the Kameni Islands volcano, and summarise recent eruption intervals from their paper on Table 1.

Following Pyle and Elliott, we presumed that the 1928 event listed on Table 1 could be treated as a continuation of the activity dated 1925-26. The 1950 eruption is regarded by Pyle and Elliott as anomalous in terms of eruption duration as a function of inter-eruption interval (their figure sixteen); we retained it here because an alternative view on their figure sixteen is that a duration/interval relationship curve should intercept close to zero duration for inter-eruption intervals tending towards zero. From these data, the mean interval for a Poisson process is $\sim 70$ years. This suggests a "base rate" annual probability of eruption
Table 1 Kameni Isl. eruption interval data (from Table 1 of Pyle and Elliott (2006)

\begin{tabular}{ll}
\hline Dates & Inter-eruption interval (to next) [yrs] \\
\hline 1950 (see text) & 62 (i.e. $>61)$ \\
$1939-41$ & 9 \\
1928 (ignored, see text) & - \\
$1925-26$ & 13 \\
$1866-70$ & 55 \\
$1707-11$ & 155 \\
$1570 / 73$ & 134 \\
\hline
\end{tabular}

in any one year of about $2 \%$, in the absence of other information.

If the memory-less Poisson assumption is questionable for this history, alternative distributions can be suggested. For instance, notwithstanding the relative paucity of data, lognormal distributions can be found that offer plausible alternative fits to the inter-eruption intervals from 1570/ 73 onwards, as shown on Figure 2 [interval data are binned into $20 \mathrm{yr}$ counts, centred at 10, 30, 50 .....150, 170 years]. Three lognormal PDFs are shown which have mean and variance parameters chosen so that the trio span a range of possible representative choices, the purpose being simply to illustrate associated uncertainty. Using Mathcad v11 functions DLNORM and Linfit (Mathsoft 2003), resulting correlation coefficients indicate elementary - and varying - measures of goodness-of-fit for these three choices, i.e. corr. coeff. $f 1=0.7$; $f 2=0.85$; $\mathrm{f} 3=0.3$, respectively. The DLNORM function $\mathrm{f} 2$, with mean $=4.5$ and s.d. $=1.42$, is the best of these three (broken/dashed black line on Figure 2).

Corresponding lognormal interval survivor functions for the three distributions, given the present (i.e. at 2012) interval had lasted 62 years, are shown on Figure 3.

Given the current inter-eruption interval was already of 62 years duration at 2012 and that a lognormal distribution is representative of recurrence behaviour, the curves on Figure 3 suggest:

$\sim 0.6 \%$ chance of eruption in the year

$\sim 3 \%$ chance of eruption in the next 5 years

$\sim 10-13 \%$ chance of eruption in the next 20 years

On this basis, the conditional probability of an eruption in the calendar year 2012 was lower by a factor of about 3 , compared to the corresponding memory-less Poisson process probability, mentioned above. For caution, the higher value is adopted for our BBN analysis, with the alternative estimate held in reserve for sensitivity tests or margin of safety analysis.

In the light of experience in Guadeloupe in 1976 (see Hincks et al. 2014 for a recent discussion in the context of 


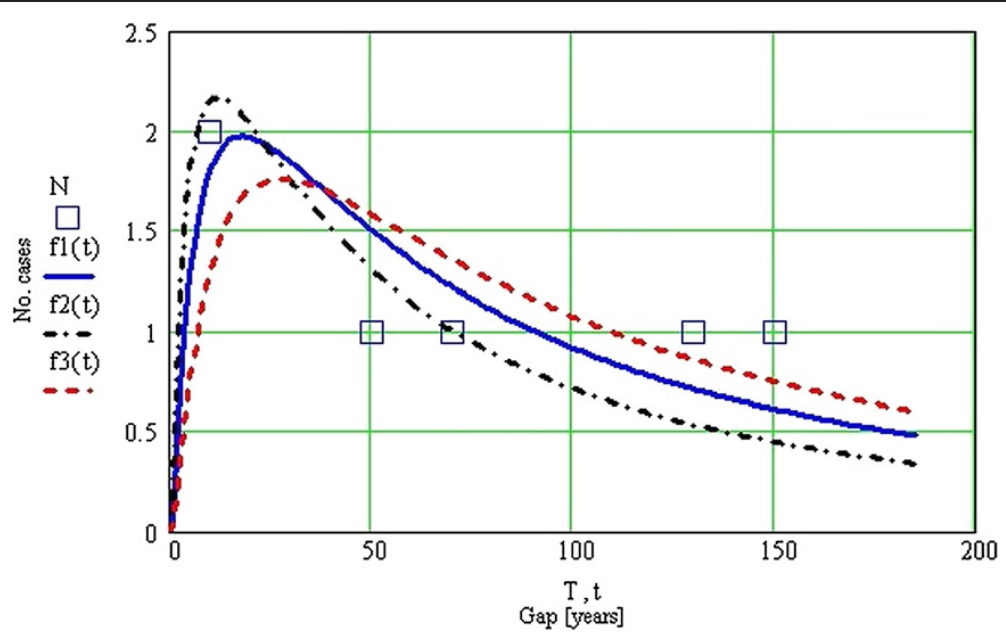

Figure 2 Santorini inter-eruption intervals: three selected lognormal PDFs are shown, chosen to span approximately the uncertainty range of plausible fits to Table 1 data (calculations with MathCad 11 - Mathsoft 2003).

hazard assessment), we also included a Failed intrusion scenario to express the possibility that even an episode of intense and prolonged unrest may not culminate in an eruption; while this follows the terminology of Hincks et al. (2014), 'failed eruption' would be an equally apt label for this scenario. Failed intrusion/eruption episodes represent a major challenge for civil protection decision making.

Moran et al. (2011) present a valuable summary of the diverse spectrum of states of unrest that can accompany a failed eruption. However, they were unable to offer any quantitative hint of how often such stillborn eruptions are the outcome of significant episodes of unrest at volcanoes generally, and there is no basis at all for assessing the probability of this scenario for Santorini. For argument's sake, we assumed that there was perhaps a 1-in-10 chance that the unrest episode at Santorini 2011-2012 was leading towards a failed eruption. This would have the effect of reducing the probabilities for eruption scenarios, derived above, by about $10 \%$. There is no way of knowing whether this over- or understated failed eruption likelihood, but it did not change substantially the eruption probability evaluations used on the BBN.

Our hurried data compilation for parameters to plug in to the BBN did not address the question of the "size" of any incipient eruption. In principle, and for a more comprehensive appraisal, the eruptive classes on the target node could be subdivided by some suitable metric of eruption size. Pyle and Elliott (2006) suggested that, following a pause of about 60 years, the next lava flow

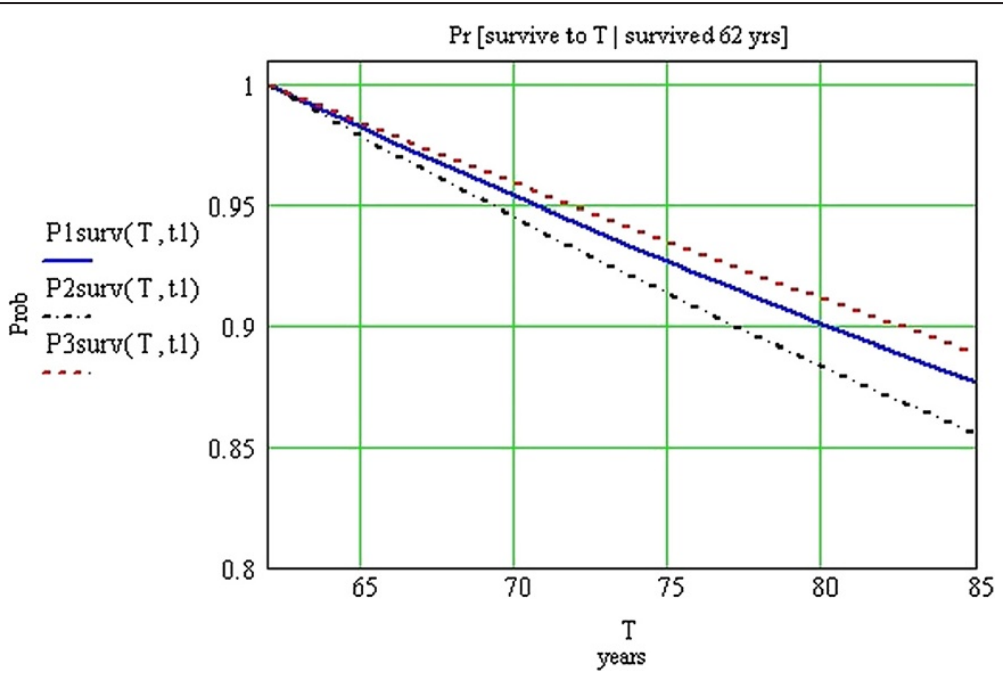

Figure 3 Lognormal survivor functions corresponding to the three PDFs shown in Figure 2, conditioned on 62 years interval since last event ( $t 1)$. 
eruption duration might be expected to be similar to that of the 1925 - 1928 event (i.e. effusive extrusion, perhaps lasting many months or a few years).

Whereas eruption size is not a variable, implicit in this probabilistic formulation is some time window for occurrence of the first next event: again, just for illustration, we assumed one year ahead was appropriate on the basis that historical data for Santorini allow us to estimate base-rate annual probabilities of event occurrence on this timescale (n.b. the state labelled Non magmatic covers all other non-magmatic causes of unrest or surface manifestations, in the chosen interval). The following baserates on Table 2 were adopted as prior probabilities in the BBN top target node.

In any random year - without additional monitoring information - there would be about a $2 \%$ chance of eruptive activity. Here we assumed a lava flow or domeforming eruption to be three times more likely than a failed intrusion episode; the latter, in turn, was enumerated five times more likely than an explosion being the first new eruptive action. This leaves a balance prior probability of $98 \%$ that no magmatic eruptive activity ensues in the following 12 months.

Although often overlooked when unrest near a volcano is being informally assessed, it is essential to include an outcome such as "Nothing happens" (here Non magmatic). The possibility will always exist that the signs of unrest are generated by some cause other than incipient eruptive/ intrusive magmatic movement or pressurization (see Conclusions and discussion, below).

Posterior probabilities on the target node are calculated by "instantiating" some or all the observation nodes upon acquiring new observations or data - i.e. the target priors are updated through the acquisition of "new" evidential information. Four basic observational monitoring nodes are included in the BBN: DC_seismicity; LP_Hybrid_Tremor; Inflation, and Gas. The node DC_seismicity stands for double-couple (i.e. rock stress failure) earthquakes, which may be either pure tectonic type or volcano-tectonic, depending upon the causal process. Where both tectonic and volcanic processes are possible causes, the nature of observed DC quakes can be ambiguous. The node labelled $\mathbf{L P}$ _Hybrid_Tremor encapsulates (non-double-couple) Long Period, Hybrid seismic events and volcanic tremor, all of which conventionally

Table 2 Base rate probabilities for alternative states of Node: Santorini_eruption_probs (Figure 1)

\begin{tabular}{ll}
\hline State & Santorini_eruption_probs \\
\hline Failed_Intrusion & $0.5 \%$ \\
LavaFlow_or_Dome_1st & $1.4 \%$ \\
Explosion_1st & $0.1 \%$ \\
Non_magmatic & $98 \%$ \\
\hline
\end{tabular}

are interpreted - if observed close to or under a volcano - as indicators of magmatic fluid or gas movement. Inflation captures the notion of ground deformation uplift due either to magma movement or pressurization, or to tectonic fault processes - another potentially ambiguous sign. The node Gas represents the detection, or nondetection, of gas flux or gases with a magmatic imprint.

Before the eruption scenario probabilities can be calculated, however, a conditional probability table (CPT, sometimes "contingency table") needs to be enumerated for each observational node. This involves quantifying the full matrix of probabilities for the particular unrest signs being present or absent, conditional on each of the volcanic states being true (n.b. inference of the latter states is unavoidable because they cannot be observed or determined independently).

Values inserted in the CPT can come from the statistics of historical precedents at the subject volcano - more commonly with additional guidance from other similar volcanoes - with derived conditional probabilities usually moderated by expert judgement. The example of the LP_Hybrid_Tremor node CPT, with illustrative probability values, is shown in Figure 4.

An alternative set of conditions are depicted in Figure 5, where the four observation nodes are each instantiated to their null or negative evidence node state: these states are labelled Background, Absent, Neutral and Uncertain, respectively; once instantiated, the eruption scenario probabilities on the main node are updated accordingly. N.b. the Netica BBN display shows rounded probabilities; precise values are tabulated against the corresponding node state selections (Table 3).

At the other extreme, Figure 6 shows the same basic BBN instantiated this time with all observational nodes set to their positive states. This very strong, joint evidence for the existence of volcanic unrest engenders significant changes in the eruption scenario probabilities: on this evidence, if activity continues there is perhaps a $77 \%$ chance

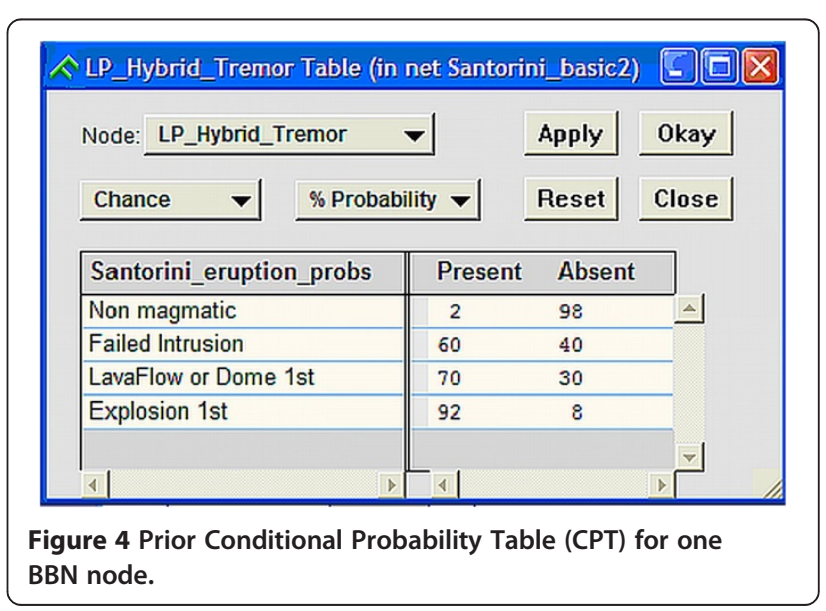




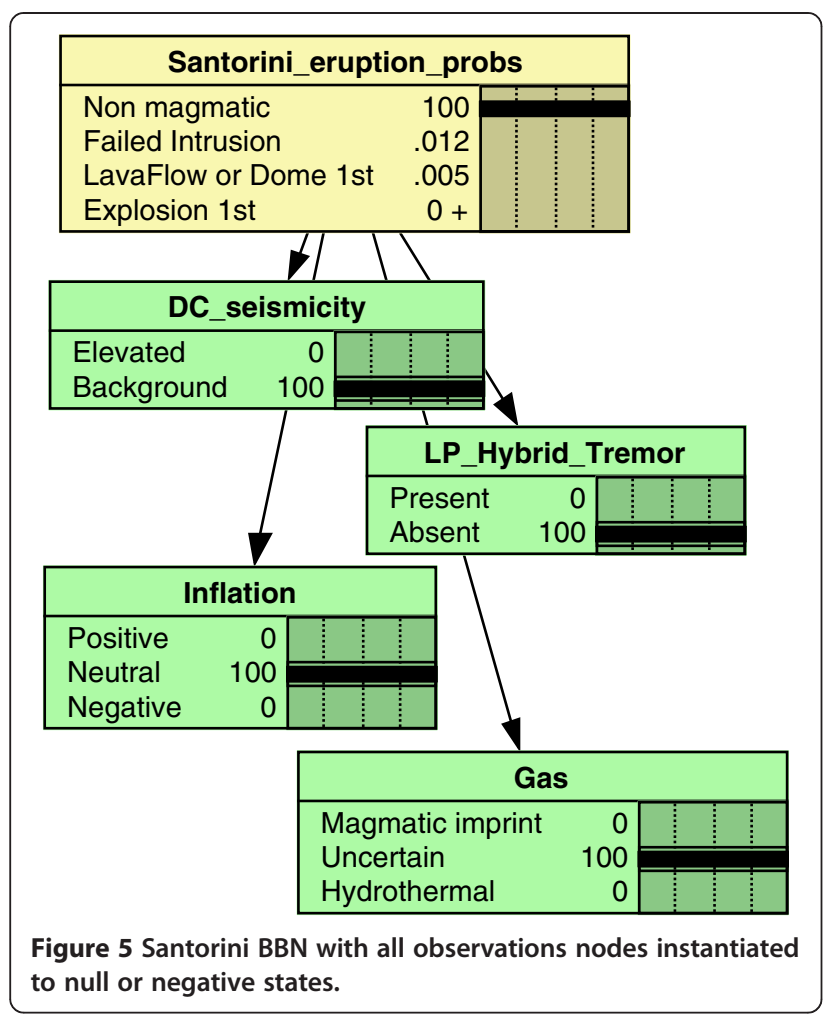

in the following twelve months of a lava flow or domeforming event, and a smaller but not-insignificant probability of an explosion. A failed intrusion episode (similar to Guadeloupe 1976) is also a real possibility: from the CPT values deployed here, this scenario is evaluated twice as likely as an explosion.

It should be borne in mind that a BBN analysis such as this should serve to inform wider decision judgements about eruptive potential - because of inevitable limitations in characterizing a complex dynamic volcano system, precise numerical inferences should not be relied on as absolute operational decisions on their own.

\section{A time-stepping BBN}

Of course, geophysical unrest - whether volcanic or seismic - is never static; levels and trends in the different indicators of unrest can and will change with time. As a consequence, inferences about the eruptive potential of a volcano system will shift as unrest progresses. Coherent, and auditable, tracking of time-evolving hazard levels is desirable, but this is a significant challenge, even with the assistance of a Dynamic Bayesian Network (DBN). Whereas a static BBN describes the state of a system without using information about its prior history, a DBN can incorporate crucial information about system evolution - in which the state of the volcano at any time is dependent on any number of past states - by relating variables to each other over subsequent time steps and modelling temporal relationships between nodes (e.g. Jensen et al. 2010). The order of such a model is the length of history, or 'memory' of the process(es) concerned.

Setting up a comprehensive DBN is, however, a nontrivial undertaking so, in the situation for Santorini where speed was important, we implemented a trade-off solution: 'a time-stepping BBN', giving us modelling inference capabilities somewhere between those of a static $\mathrm{BBN}$ and those of a DBN. Taking the BBN example from the previous section, Figure 7 shows one way this could be set up for an unrest episode with four basic data streams, such as that at Santorini: after an initial assessment, two time-step updates are illustrated, identifying trends or trend changes in the unrest indicators. The time-step is not defined in this illustration, but typically could be on a scale of days, weeks or months, depending upon circumstances. Enumerating the conditional probabilities for the CPTs in such a BBN is a major task, and developing a time-stepping BBN for operational application requires much thought and work. Figures 8 and 9 depict two hypothetical sets of update instantiations (nodes shaded green), showing indicatively how changes in calculated eruption probabilities might unfold with time

Table 3 BBN evaluated eruption probabilities for instantiated node states on Figure 5 (values on figure are rounded)

\begin{tabular}{|c|c|c|c|}
\hline \multirow{2}{*}{$\begin{array}{l}\text { Observation node } \\
\text { Gas }\end{array}$} & \multicolumn{3}{|c|}{ State instantiated (selected $=1$ ) } \\
\hline & Magmatic_imprint & Uncertain & Hydrothermal \\
\hline & 0 & 1 & 0 \\
\hline \multirow[t]{2}{*}{ Inflation } & Positive & Neutral & Negative \\
\hline & 0 & 1 & 0 \\
\hline \multirow[t]{2}{*}{ DC_seismicity } & Elevated & Background & \\
\hline & 0 & 1 & \\
\hline \multirow[t]{2}{*}{ LP_Hybrid_Tremor } & Present & Absent & \\
\hline & 0 & 1 & \\
\hline \multicolumn{4}{|c|}{ Corresponding probabilities for Node: Santorini_eruption_probs } \\
\hline Non_magmatic & Failed_Intrusion & LavaFlow_or_Dome_1st & Explosion_1st \\
\hline $99.98 \%$ & $0.012 \%$ & $5.5 \times 10^{-3} \%$ & $3 . \times 10^{-5} \%$ \\
\hline
\end{tabular}




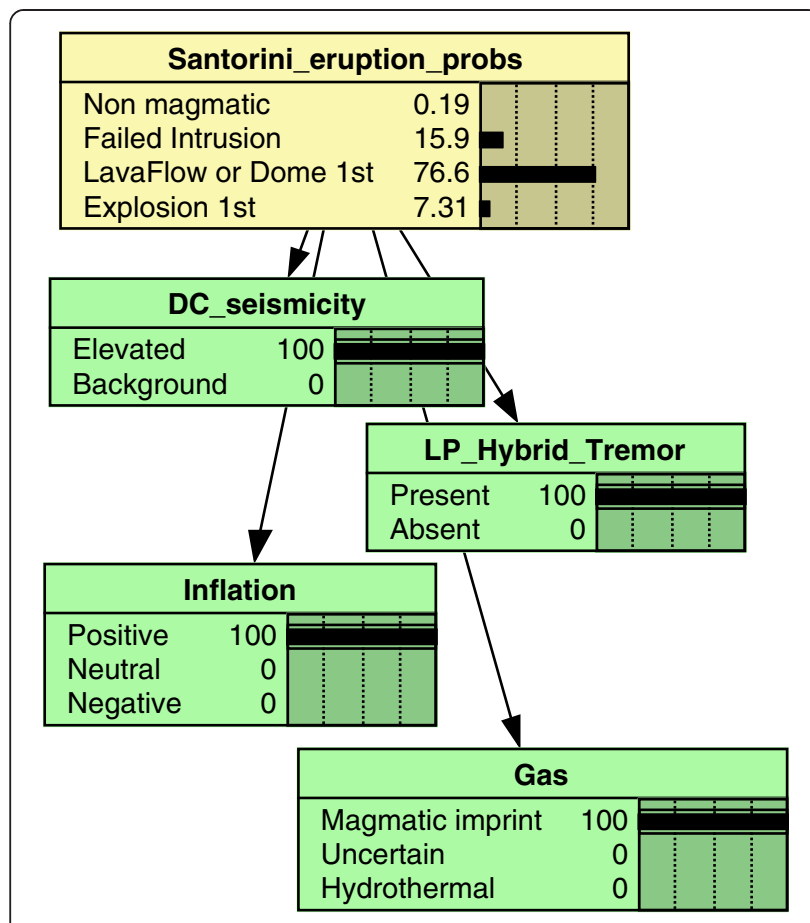

Figure 6 Santorini BBN with all observation nodes instantiated to positive states. and changing unrest indications. If a full DBN can be implemented, the possibilities and degrees of sophistication that can be achieved are almost limitless.

\section{Extending the BBN for additional datastreams}

The preceding examples illustrated BBN applications when there are just four unrest symptoms. Modern volcano monitoring can entail multi-parameter diagnostics, including different techniques for measuring the same fundamental variable (e.g. deformation gauged simultaneously with GPS and InSAR). Nowadays, the number of such indicators easily exceeds any feasible chance of assimilating mentally all strands of evidence and inferring the implications for hazard level without the assistance of a structured procedure. An example of what might be involved is shown in Figure 10, with instantiated nodes shaded pink (n.b. not all such monitoring techniques were deployed at Santorini, and data were not necessarily available from others as BBN entries).

Even with all fifteen of these indicative nodes and compound $\mathrm{CPT}$ relationships, this is a substantial but still tractable BBN. Note that this model exemplifies an extension of the conversation to secondary indicators, such as Sea_temp and Sea_state, in relation to which observations of above ambient temperature or of bubbling are presumed to be evidence of elevated (submarine) gas output.

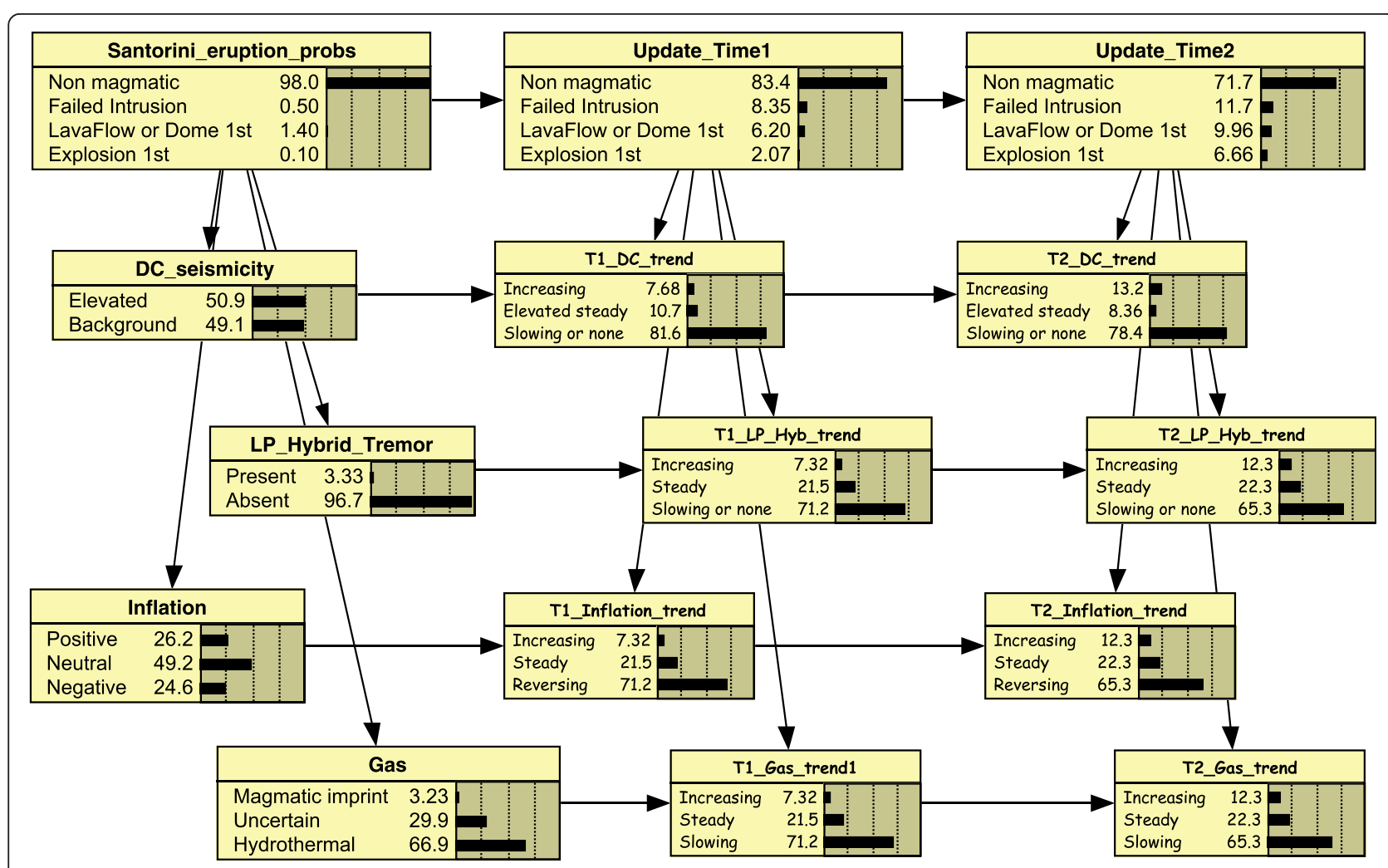

Figure 7 A specimen time-stepping BBN for Santorini unrest, with four evidence streams. 


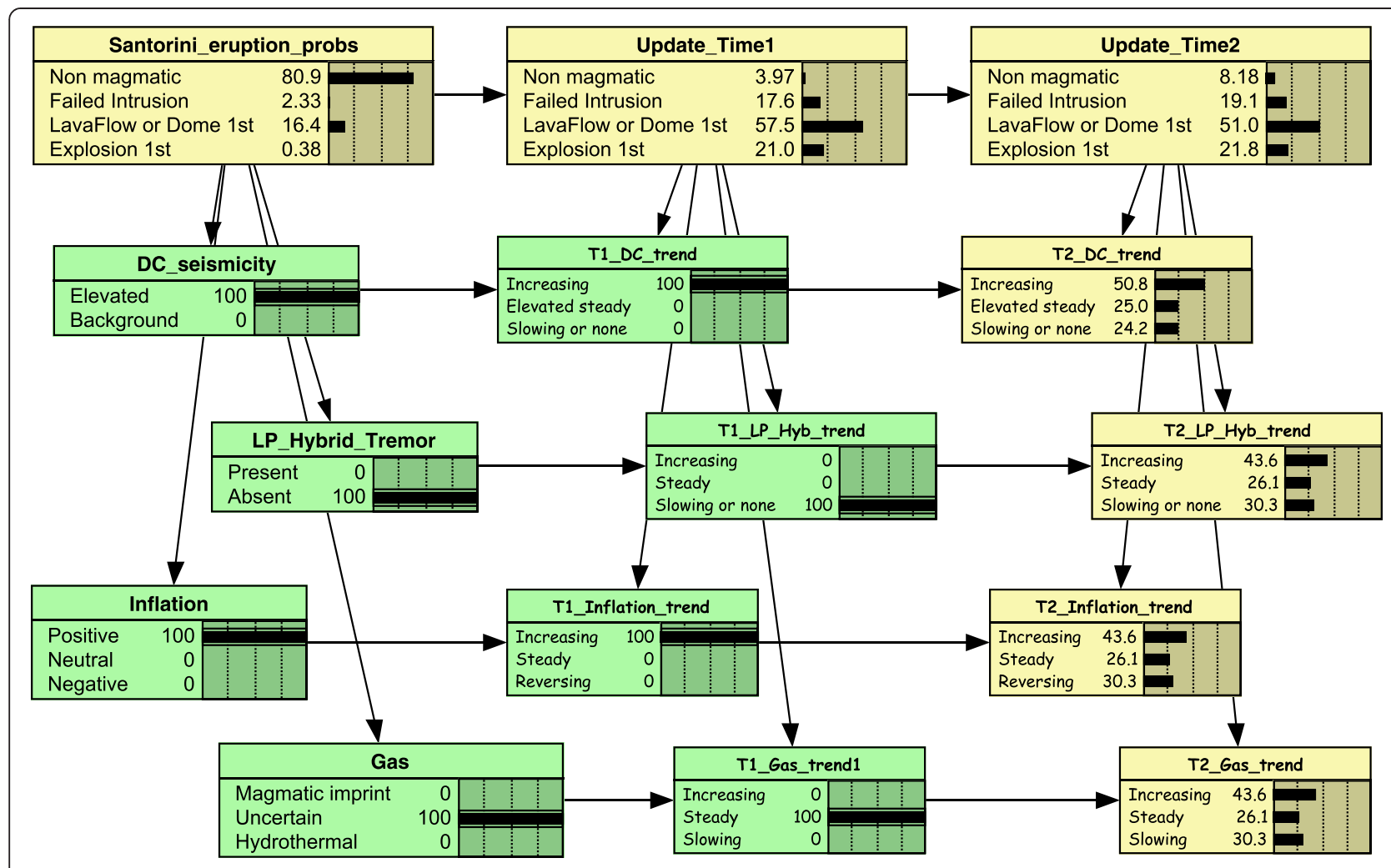

Figure 8 Time-stepping Santorini BBN, with two time steps hypothetically instantiated in sequence (rows $2-5$, first two column sets); note changes to probabilities on all target nodes (upper row), forwards and backwards.

In this example a node Felt_quakes is also included, with discrete enumerated states quantified in terms of number of events in a given time in specified ranges. This contrasts with the other nodes, which simply express more qualitative categorical states. The reason for including such a node here is to exemplify how one particular manifestation of volcanic unrest can be construed to make it is coherent with older, pre-instrumental historical information. The latter data can provide valuable and robust benchmark rates of occurrence from previous eruptions and episodes of unrest at this or other volcanoes, and could be invaluable diagnostic information which, otherwise, cannot be easily included in the eruption scenario probability calculations.

One particular strength of the BBN approach, not illustrated by Figure 10, is what happens if observational data becomes unavailable due to instrument loss or is incompletely reported due to technical difficulties. In this case, the Bayes' Rule formulation offers a powerful means for handling missing data, which can be regarded in a BBN model in just the same way as an unknown or latent variable. For instance, if the Felt_quakes node is not instantiated, then the BBN will calculate the expected mean rate of felt earthquakes and an estimate of the statistical spread about this rate, given the states of all other nodes in the network. This is possible because a
BBN can be parameterized with generic or analogue relationships between all pairs of variables, and instantiating any node forces a recalculation of any un-instantiated dependent node through the conditional probability relationships. In this way a BBN can elegantly handle missing values in prior distributions by inference from other parameter findings - an extensive literature expounds the principles (e.g. Daniels and Hogan 2008 is a recent text).

\section{Linking eruption scenario probabilities to ash and gas hazards}

As just described, the BBN approach provides a transparent framework for deriving eruption scenario probabilities which can be used then as initiating likelihoods for quantitative assessments of contingent hazards and risks. For instance, stochastic models of ash and gas hazard are available to describe the dispersal of ash and $\mathrm{SO}_{2}$ during an eruption with defined source parameters; such models were utilized by Jenkins et al. (Assessment of ash and gas hazard for future eruptions at Santorini Volcano, Greece. forthcoming) for the Santorini case. In terms of ashfall hazards, two alternative scenarios might be adopted as the most likely or expected eruptions, based on an understanding of explosive activity during historic eruptions (e.g. Parks et al. 2012): these eruptions can be characterized by slow lava extrusion over periods of 2 to 4 years with weak but 

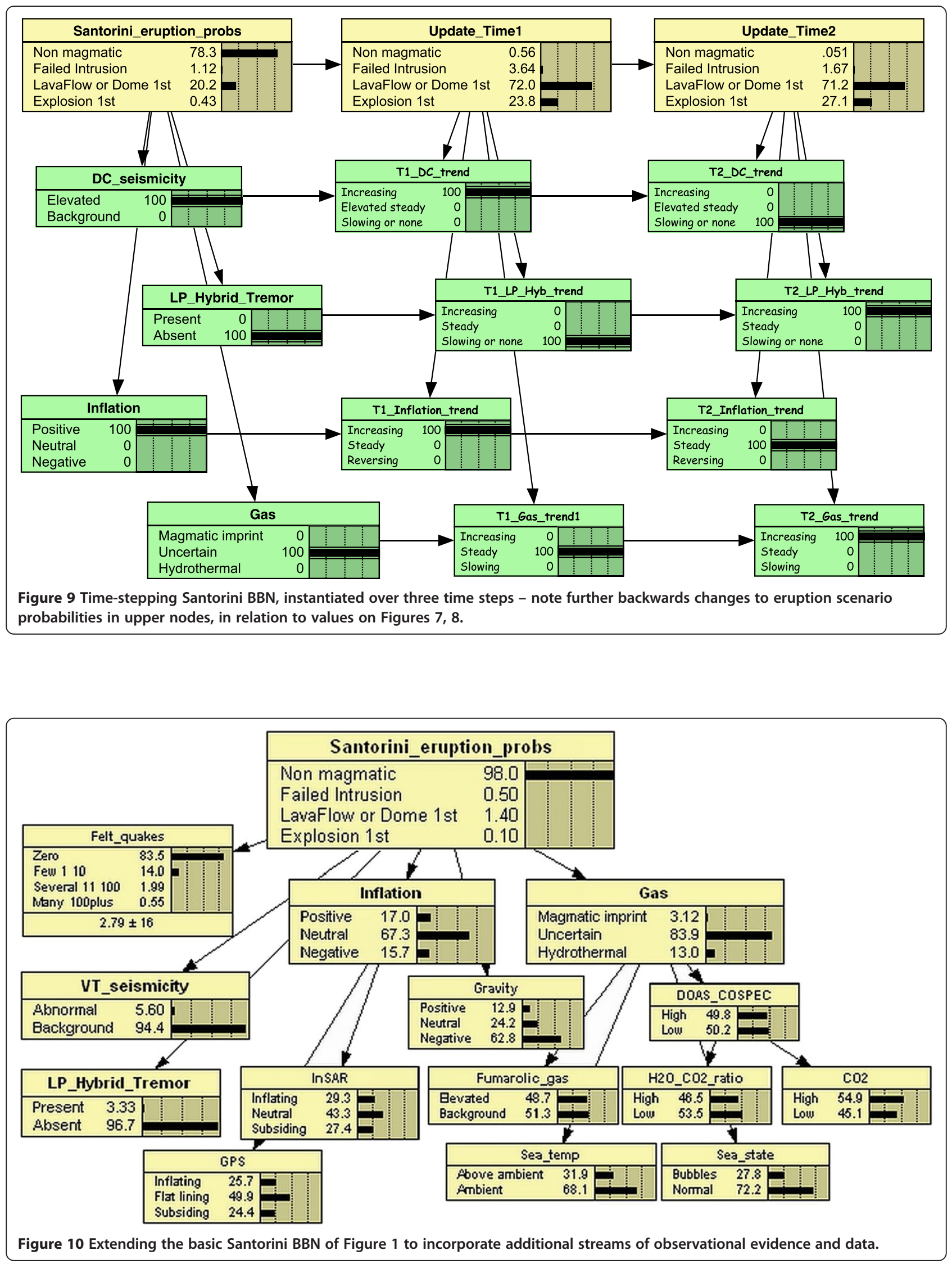
persistent explosions and ash venting. A third, more extreme, scenario is a sub-Plinian explosive eruption which, although one has not happened since $1650 \mathrm{AD}$, is commonplace in the geological record of Thera. For crisis response purposes, this latter scenario might be regarded as a "worst considered case".

Outputs from such dispersion models take the form of probabilistic maps and exceedance probability curves for key locations (Jenkins et. al., Assessment of ash and gas hazard for future eruptions at Santorini Volcano, Greece. forthcoming). Those findings can be conditioned on the initiating eruption probability, as determined by the eruption BBN analysis approach described here, and on eruption style, intensity, duration and other factors.

\section{Conclusions and discussion}

A key conclusion from this exercise, and from experience with BBNs at other volcanoes (e.g. Wadge and Aspinall 2014), is that even with just three or four basic observation indicators, it is not feasible or defensible to attempt to judge mentally the implications of unrest signs for hazard assessment purposes - rational enumeration using Bayes' Rule is essential for reliable estimation of probabilities in the presence of uncertainty. The structured graphical procedure afforded by the $\mathrm{BBN}$ technique offers an efficient and tractable way to manage the problem. Once this step is taken, the efficiency of a BBN means there is a compelling argument to extend it to incorporate all strands of evidence, thus maximizing diagnostic power for supporting decision preparedness. That said, a volcanic hazard assessment, such as that needed by civil protection authorities for such situations as Santorini, should, if possible, be elaborated in detail before significant unrest develops and with the involvement of as many knowledgeable experts as can be mustered for elicitation and BBN model definition and parameterization.

Although the BBN approach outlined above was developed urgently during the period of heightened official concern in the recent Santorini unrest, the various eruption scenario probabilities that were obtained - conditional on the enumeration of different strands of observational evidence by one person (WPA) - serve to demonstrate the importance of considering not only positive pieces of (volcanic) evidence but also negative evidence, alternative hypotheses, and null outcomes. For instance, at the time of the 2011-2012 unrest it was not abundantly certain that the caldera earthquakes and uplift were due solely to magmatic changes or movements - there may have been a strong tectonic element involved, perhaps even exclusively tectonic. Thus while the unrest that was centered in the Thera caldera might have been the result of volcanotectonic interactions (e.g. Feuillet 2013), it is also plausible that it was due to wider tectonic stresses, not simply or necessarily volcanic in origin. Local earthquake hazard lies outside the scope of the present discussion, but if the possibility of a seismotectonic cause is ignored or discounted - something that can easily happen with volcanologists focusing on their specialism in a geophysical crisis - the corollary is that perceptions of volcanic risk and related implications may be inflated. Indeed, not recognizing the possibility that short-term seismic hazard levels could have been elevated at the time of unrest might be more disastrous: whereas volcanic activity might cause some disruption and several casualties, at worst, a significant local earthquake or earthquake sequence could be the cause of a major casualty toll on Santorini (a counterpart analysis will be reported elsewhere).

Although constructing a BBN for the different possibilities does not guarantee all pitfalls can be avoided, the danger of misstating hazards and risks is greatly reduced if a structured and comprehensive approach is taken to quantification of all forms of potential natural hazards. Given what has happened to scientific advisers recently in relation to the 2009 L'Aquila, Italy, earthquake disaster (Editorial, Nature Geoscience 2013), a rational framework for assessing uncertain scientific evidence in unrest circumstances surely now must be a sine qua non for Earth scientists involved in hazard and risk assessment work (Aspinall 2011).

In the present case, the way in which the volcanic hazard situation at Santorini was evaluated urgently using BBNs is not held up as an exemplar of how such an assessment should be done in all circumstances; however it may provide helpful insights into formalized probabilistic methods for handling uncertain data and information under crisis conditions.

\section{Endnote}

${ }^{a}$ In connection with the 2011-2012 Santorini unrest situation, acquisition of scientific advice for official purposes was led by the Chief Scientific Adviser to the UK Government, through his Scientific Advisory Group for Emergencies (SAGE). Ministries and departments of government that had need of this advice included the Government Office of Science, the Foreign and Commonwealth Office, the Cabinet Office, the Home Office, Departments of Health, Defence and Transport, and other related agencies and organizations.

\section{Abbreviations}

BBN: Bayesian belief network; CPT: Conditional probability table (sometimes: contingency table); PDF: Probability distribution function.

\section{Competing interests}

The authors declare that they have no competing interests.

\section{Authors' contributions}

Both authors contributed to concept development, interpretations and inferences; WPA undertook the probabilistic BBN analyses, prepared the draft manuscript and figures. Both authors have read and approved the final version. 


\section{Acknowledgements}

This work was supported in part by the European Community's Seventh Framework Programme [FP7/2007-2013] under grant agreement $n^{\circ} 265138$ Project 265138 MATRIX: New methodologies for multi-hazard and multi-risk assessment methods for Europe; and in part (WPA) by an ERC Advanced Research Grant (VOLDIES) to Prof. RSJ Sparks at Bristol University. We are grateful to two reviewers for very helpful comments.

\section{Author details}

${ }^{1}$ School of Earth Sciences and Cabot Institute, University of Bristol, Wills Memorial Building, Queen's Road, Bristol BS8 1RJ, UK. ${ }^{2}$ Aspinall \& Associates, Cleveland House, High Street, Tisbury SP3 6HF, UK. ${ }^{3}$ Risk Management Solutions, Peninsular House, 30 Monument Street, London EC3R 8NB, UK.

Received: 31 March 2014 Accepted: 1 August 2014

Published online: 10 September 2014

\section{References}

Aguilera PA, Fernandez A, Fernandez R, Rumi R, Salmeron A (2011) Bayesian networks in environmental modeling. Environ Model Software 26:1376-1388

Aspinall W (2011) World view - check your legal position before advising others Nature 477:251, doi:10.1038/477251a

Aspinall WP, Carniel R, Jaquet O, Woo G, Hincks T (2006) Using hidden multi-state Markov models with multi-parameter volcanic data to provide empirical evidence for alert decision-support. J Volcanol Geotherm Res 153:112-124

Aspinall WP, Woo G, Voight B, Baxter PJ (2003) Evidence-based volcanology; application to eruption crises. J Volcanol Geotherm Res: Putting volcano seismology in a physical context; in memory of Bruno Martinelli 128:273-285

Cowell R, Verrall R, Yoon Y (2007) Modeling operational risk with Bayesian networks. J Risk Insur 74(4):795-827, doi:10.1111/j.1539-6975.2007.00235.x

Daniels MJ, Hogan JW (2008) Missing data in longitudinal studies: strategies for Bayesian modelling and sensitivity analysis. Chapman \& Hall, Boca Raton FL, pp 303

Darwiche A (2009) Modeling and Reasoning With Bayesian Networks. Cambridge University Press, New York

Fenton NE, Neil MD (2012) Risk Assessment and Decision Analysis with Bayesian Networks. CRC Press, Boca Raton FL

Feuillet N (2013) The 2011-2012 unrest at Santorini rift: stress interaction between active faulting and volcanism. Geophys Res Lett 40:3532-3537

Hincks TK (2007) Probabilistic Volcanic Hazard and Risk Assessment. Unpublished PhD Thesis. University of Bristol, UK, pp 234

Hincks TK, Komorowski J-C, Sparks RSJ, Aspinall WP (2014) Retrospective analysis of uncertain eruption precursors at La Soufrière volcano, Guadeloupe, 1975-77: volcanic hazard assessment using a Bayesian belief network approach. J Appl Volcanol 3(3) doi:10.1186/2191-5040-3-3

Jensen FB, Jensen FV, Nielsen TD, Graven-Nielsen T (2010) Bayesian Networks and Decision Graphs (Second Edition). Springer, New York, pp 448

Kappes MS, Keiler M, von Elverfeld K, Glade T (2012) Challenges of analysing multi-hazard risk: a review. Nat Hazards 64:1925-1938, doi:10.1007/s11069012-0294-2

Kousky C, Cooke R (2012) The Value of Information in a Risk Management Approach to Climate Change. In: Laxminarayan R, Macauley MK (eds) Chap 2 in: The Value of Information. Springer, Netherlands, pp 19-43

Marzocchi W, Garcia-Aristizabal A, Gasparini P, Mastellone ML, Di Ruocco A (2012) Basic principles of multi-risk assessment: a case study in Italy. Nat Hazards 62:551-573, doi:10.1007/s11069-012-0092-X

Marzocchi W, Sandri L, Gasparini P, Newhall C, Boschi E (2004) Quantifying probabilities of volcanic events: the example of volcanic hazard at Mount Vesuvius. J Geophys Res 109, B11201, doi:10.1029/2004JB003155

Marzocchi W, Sandri L, Selva J (2008) BET_EF: a probabilistic tool for long- and short-term eruption forecasting. Bull Volcanol 70(5):623-632

Mathsoft (2003) Mathcad v11.2a Mathsoft Engineering \& Education Inc., http://www.ptc.com. Accessed 16 August 2014

Moran S, Newhall C, Roman D (2011) Failed magmatic eruptions: late-stage cessation of magma ascent. Bull Volcanol 73:115-122, doi:10.1007/s00445-010-0444- $x$

Nature Geoscience (2013) Editorial: communication at risk. Nat Geosci 6:77

Neil M, Fenton N, Tailor M (2005) Using Bayesian Networks to model expected and unexpected operational losses. Risk Analysis 25:963-972. doi:10.1111/ j.1539-6924.2005.00641.x

Newhall C, Hoblitt R (2002) Constructing event trees for volcanic crises. Bull Volcanol 64(1):3-20, doi:10.1007/s004450100173
Newman AV, Stiros S, Feng L, Psimoulis P, Moschas F, Saltogianni V, Jiang $Y$, Papazachos C, Panagiotopoulos D, Karagianni E, Vamvakaris D (2012) Recent geodetic unrest at Santorini Caldera, Greece. Geophys Res Letts 39, L06309. doi:10.1029/2012GL051286

NorsysSoftware Corp (2014) Netica v4.14. http://www.norsys.com. Accessed 16 August 2014

Papoutsis I, Papanikolaou X, Floyd M, Ji KH, Kontoes C, Paradissis D, Zacharis V (2013) Mapping inflation at Santorini volcano, Greece, using GPS and InSAR. Geophys Res Letts 40:267-272

Parks MM, Biggs J, England P, Mather TA, Nomikou P, Palamartchouk K, Papanikolaou X, Paradissis D, Parsons B, Pyle DM, Raptakis C, Zacharis V (2012) Evolution of Santorini Volcano dominated by episodic and rapid fluxes of melt from depth. Nature Geosci 5(10):749-754

Pyle DM, Elliott JR (2006) Quantitative morphology, recent evolution, and future activity of the Kameni Islands volcano, Santorini, Greece. Geosphere 2(5):253-268

Siebert L, Simkin T, Kimberly P (2010) Volcanoes of the World, 3rd edn. University of California Press, Berkeley, pp 568

Sobradelo R, Martí J (2010) Bayesian event tree for long-term volcanic hazard assessment: Application to Teide - Pico Viejo stratovolcanoes, Tenerife, Canary Islands. J Geophys Res 115, B05206, doi:10.1029/2009JB006566

Spiegelhalter DJ, Dawid A, Lauritzen SL, Cowell R (1993) Bayesian-analysis in expert-systems. Stat Sci 8:219-247

Wadge G, Aspinall WP (2014) A review of volcanic hazard and risk assessments at the Soufrière Hills Volcano, Montserrat from 1997 to 2011. In: Wadge G, Robertson R, Voight B (eds) Geol Soc Memoir 39: The Eruption of Soufriere Hills Volcano, Montserrat, from 2000 to 2010. Geological Society of London, pp 439-456

\section{doi:10.1186/s13617-014-0012-8}

Cite this article as: Aspinall and Woo: Santorini unrest 2011-2012: an immediate Bayesian belief network analysis of eruption scenario probabilities for urgent decision support under uncertainty. Journal of Applied Volcanology 2014 3:12

\section{Submit your manuscript to a SpringerOpen ${ }^{\circ}$ journal and benefit from:}

- Convenient online submission

- Rigorous peer review

- Immediate publication on acceptance

- Open access: articles freely available online

- High visibility within the field

- Retaining the copyright to your article

Submit your next manuscript at springeropen.com 